TITLE:

\title{
ADDITIONAL REPORT ON CALANOID COPEPODS FROM THE IZU REGION PART 2. EUCHIRELLA AND PSEUDOCHIRELLA
}

$\operatorname{AUTHOR}(\mathrm{S})$ :

Tanaka, Otohiko; Omori, Makoto

\section{CITATION:}

Tanaka, Otohiko ...[et al]. ADDITIONAL REPORT ON CALANOID COPEPODS FROM THE IZU REGION PART 2. EUCHIRELLA AND PSEUDOCHIRELLA. PUBLICATIONS OF THE SETO MARINE BIOLOGICAL LABORATORY 1969, 17(3): 155-169

ISSUE DATE:

1969-11-29

URL:

http://hdl.handle.net/2433/175596

RIGHT: 


\title{
ADDITIONAL REPORT ON CALANOID COPEPODS FROM THE IZU REGION PART 2. EUCHIRELLA AND PSEUDOCHIRELLA
}

\author{
OTонIKo TANAKA ${ }^{13}$ and MAKoto OMORI ${ }^{23}$
}

With 5 Text-figures

Following the previous report on Euchaeta and Pareuchaeta (TANAKA and OMORI, 1968), the present paper deals with Euchirella and Pseudochirella in the Izu region. The sampling method, position, depth, and date are given in the above cited paper.

Regarding Euchirella from the Pacific and Indian Oceans, the authors confirmed previously the existance of 15 species including E. tanseii (TANAKA and OMORI, 1969). In Japanese waters the distribution of 13 species of Euchirella, namely, amoena, bella, bitumida, curticauda, galeata, maxima, messinensis indica, orientalis, pulchra, rostrata, tanseii, truncata, and venusta, have been known (Mori, 1937; TANaka, 1957; OMori, 1965; Furuhashi, 1965; TANAKA and OMORI, 1969). In the present collection a total 13 species listed in Table 1 are obtained from the Izu region.

Table 1. List of species

\begin{tabular}{ll} 
Euchirella & 10. rostrata (Claus) \\
1. amoena Giesbrecht & 11. truncata Esterly \\
2. bella Giesbrecht & 12. unispina Park \\
3. bitumida With & 13. venusta Giesbrecht \\
4. curticauda Giesbrecht & Pseudochirella \\
5. galeata Giesbrecht & 1. polyspina Brodsky \\
6. maxima Wolfenden & 2. pustrifera (Sars) \\
7. messinensis indica (Vervoort) & 3. spinifera Brodsky \\
8. orientalis Sewell & 4. tuberculata Tanaka \\
9. pulchra (Lubbock) & 5. vervoorti sp. nov. \\
\hline
\end{tabular}

On the other hand, at least 24 species of Pseudochirella have been reported from the Pacific and Indian Oceans. They are, 1. P. bilobata Vervoort, 2. P. cryptospina (SArs), 3. P. elongata (Wolfenden), 4. P. dentata (A. Scott), 5. P. divaricata (SARs), 6. P. dubia (SARs), 7. P. gibbera Vervoort, 8. P. granulata (A. ScotT), 9. P. gurjanovae

1) 60 Sangenchaya-machi, Setagaya-ku, Tokyo

2) Ocean Research Institute, University of Tokyo, Nakano, Tokyo

Publ. Seto Mar. Biol. Lab., XVII (3), 155-169, 1969. (Article 6) 
Brodsky, 10. P. hirsuta (Wolfenden), 11. P. limata Grice and Hulsemann, 12. $P$. magna (Wolfenden), 13. P. maresoni Vervoort, 14. P. notacantha (SARS), 15. P. obtusa (SARs), 16. P. pacifica Brodsky, 17. P. polyspina Brodsky, 18. P. pustulifera (SARs), 19. P. scopularis (SARs), 20. P. semispina VERvoort, 21. P. spinifera Brodsky, 22. $P$. squalida Grice and Hulsemann, 23. $P$. tuberculata Tanaka, and 24. P. tuberosa Grice and Hulsemann. Among them, 14 species (species 3, 5, 9-11, 15-19, 21-24) were found in the Pacific Ocean excluding the waters around Malay Archipelago. Pseudochirella are generally bathypelagic and the number of specimens sampled is usually very few. Therefore, in many species either female or male is unknown. Fifteen species $(1,3-5,7,8,10,11,17-20,22-24)$ have been described only by the female specimen, and 3 species $(9,16,21)$ have been established only by the male specimen. Moreover, the adult females of the species 2 and 14 are still unknown. Several species $(1,7,8,10)$ were reported by the single specimen, and they have not been collected again since they were first described. Although the species have each characteristic features both in the female and the male, there remains some hesitation in deciding a male specimen as the corresponding female. Probably, some species of the genus will be synonymized by the detail examination with large collection in

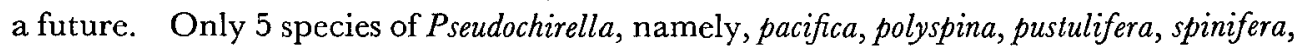
and tuberculata have been reported from Japanese waters (TANAKA, 1957; FuruHASHI, 1965). A new species $P$. vervoorti is described in this paper. All of the specimens are deposited in the Ocean Research Institute.

The authors wish to express our appreciation to Prof. R. Marumo of the Ocean Research Institute for his helpful criticism and kind reading of the manuscript.

\section{EUCHIRELLA GIESBRECHT, 1888}

Euchirella amoena GIESBRECHT, 1888

Euchirella amoena, PARK, 1968, p. 550; TANAKA and OMORI, 1969, p. 37

Occurrence: Sta. 118, 1 우.

Euchirella bella GIESBRECHT, 1888

Euchirella bella, TANAKA and OMORI, 1969, p. 38, fig. 2, a-1.

Occurrence: Sta. 84-2, 1 ð; Sta. 97-2, 2 ㅇ․

\section{Euchirella bitumida, WITH 1915}

Euchirella bitumida, TANAKA and OMori, 1969, p. 40, figs. 3, a-g.

Occurrence: Sta. 84-2, 1 \%; Sta. 95, 1 9 ; Sta. 97-2, 3; Sta. 98, 2q; Sta. 108,

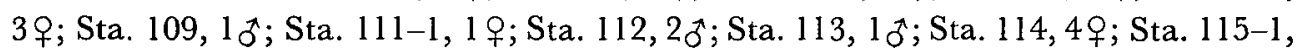


13q; Sta. 115-2, 8q; Sta. 116, 3q; Sta. 117-1, 1q; Sta. 118, 1q; Sta. 119, $2 q$; Sta. 121-1, 3우 Sta. 122, 1 ㅇ․

\section{Euchirella curticauda Giesbrecht, 1888}

Euchirella curticauda, TANAKA and OMORI, 1969, p. 42.

Occurrence: Sta. 84-2, 3q; Sta. 93-2, 3q; Sta. 94-1, 1q; Sta. 95, 2 q, 1ơ; Sta. 96, 3q; Sta. 97-2, 3q; Sta. 98, 2q, 10; Sta. 108, 2 ; ; Sta. 109, 2o, 1o; Sta. 110, 2 \% Sta. 111-1, 5q; Sta. 111-2, 4우 Sta. 112, 2우 Sta. 114, 4; Sta. 115-1, 2q; Sta. 121-2, 1 ‥

Remarks: This is one of the most common species in the Izu region. However, the population decreased greatly in number in the southern waters of the Kuroshio.

\section{Euchirella galeata GIESBRECHT, 1888}

Euchirella galeata, TANAKA and OMORI, 1969, p. 43, fig. 4, a-k.

Occurrence: Sta. 98, 1 9.

\section{Euchirella maxima WOLFENDEN, 1905}

(Fig. 1, a-g)

Euchirella maxima, TANAKA and OMORI, 1969, p. 48.

Occurrence: Sta. 96, 1q; Sta. 120, 1\%; Sta. 122, 1 \%

Remarks: Female, 7.00-7.50 mm. Large ventral protuberance of the genital segment of the present specimens is visible on the right side in dorsal view, though it has never been illustrated in the previous papers. The 1st basal segment of the 5 th leg bears a large spine: the spine itself covers 5 spinules. The species is distributed usually in the layers between 200 and $500 \mathrm{~m}$ in the Izu region.

\section{Euchirella messinensis indica (VERVOORT, 1949)}

Euchirella indica VERVOoRT, 1949, p. 23, figs. 8b, 9b, 11, 12a, b.

Euchirella messinensis indica, TANAKA and OMORI, 1969, p. 48, fig. 6, f-m.

Occurrence: Both female and male were collected at all sampling stations.

Remarks: The detail diagnosis of the species was given by TANAKA and OMORl (1969). This is the most common Euchirella in the Izu region.

\section{Euchirella orientalis SEWELL, 1929}

Euchirella orientalis, TANAKA and OMORI, 1969, p. 52, fig. 7, a-i. 

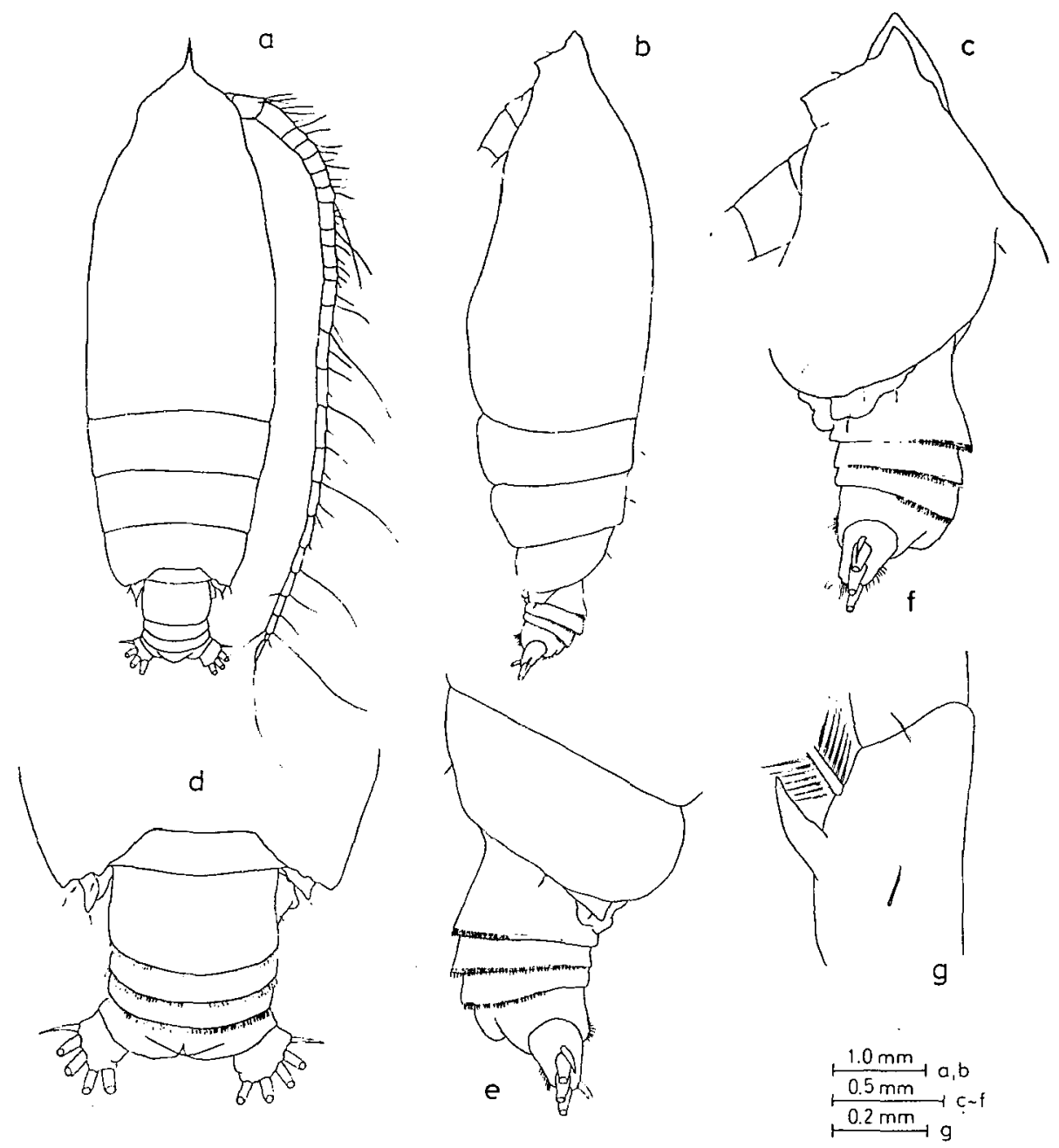

Fig. 1. Euchirella maxima Wolfenden, female: a, whole animal, dorsal view; b, the same, lateral view; c, head, lateral view; $d$, last thoracic segment and abdomen, dorsal view; $e$, the same, lateral view from right side; $f$, the same, lateral view from left side; $g$, 1 st basal segment of 4 th leg.

Occurrence: Both sexes were found at all stations except Stas. 94-1, 98, 113, and 116.

Remarks: The species is also very common in the investigated area. The distribution appears to be restricted in the water deeper than $150 \mathrm{~m}$.

\section{Euchirella pulchra (LuвBOCK, 1856)}

Euchirella pulchra, TANAKA and OMORI, 1969, p. 55, fig. 8, a-f. 
Occurrence: Sta. 84-2, 1우 Sta. 93-2, 1ðં; Sta. 97-2, 1; Sta. 98, 1 ㅇ․

\section{Euchirella rostrata (CLAUS, 1866)}

Euchirella rostrata, TANAKA and OMORI, 1969, p. 56.

Occurrence: Sta. 97-2, 1q; Sta. 98, 1\%; Sta. 108, 6\%; Sta. 109, 3q; Sta. 110, 13q; Sta. 111-1, 17o; Sta. 111-2, 8q; Sta. 112, 18q; Sta. 113, 1 $q$; Sta. 114, 2 ; Sta. 115-1, 7q; Sta. 115-2, 10q; Sta. 117-2, 1q; Sta. 118, 19q; Sta. 119, $4 q$; Sta. 120, 20; Sta. 121-1, 3ㅇ; Sta. 121-2, 1우 Sta. 122, 22 ..

\section{Euchirella truncata ESTERLY, 1911}

Euchirella truncata, PARK, 1968, p. 545, pl. 5, figs. 15-22; TANAKA and OMORI, 1969, p. 57, fig. 9, a-g.

Occurrence: Sta. 115-1, 1\%; 1ठ; Sta. 115-2, 2o; Sta. 117-1, 1\%; Sta. 118, 3q; Sta. 119, 3여 Sta. 120, 2 ㅇ․

\section{Euchirella unispina PARK, 1968}

Euchirella unispina PARK, 1968, p. 546, pl. 6, figs. 1-21, pl. 7, figs. 1-11.

Euchirella acuta TANAKA and OMORI, 1969, p. 34, fig. 1, a-n.

Occurrence: Sta. 115-1, 1 우.

Remarks: Female, $4.64 \mathrm{~mm}$. E. acuta reported by TANAKA and OMORI (1969) from the eastern equatorial Pacific appears to be identical with $E$. unispina, though there are slight differences in the proportional lengths of the abdominal segments and furca in both sexes, and in the structure of the male's lst pair of legs. The species seems to have fairly wide distribution in the Pacific Ocean, from the Izu region to off Peru.

\section{Euchirella venusta GIESBRECHT, 1888}

Euchirella venusta, TANAKA and OMORI, 1969, p. 59, fig. 10, a-i.

Occurrence: Sta. 83, 1 9 ; Sta. 94-1, 1\%; Sta. 96, 2; Sta. 97-2, 1 9 ; Sta. 98, 1 ; Sta. 109, 1q; Sta. 114, 4q; Sta. 117-1, 1\%; Sta. 121-2, 2; Sta. 122, 1 q

Remarks: Female of the species can be distinguished from other members of the genus by the following characteristics: 4 setae on the inner lobe and 5 setae on the outer lobe of the terminal segment of the endopod of the 2nd antenna; 2 spines on the 1st basipodal segment of the 4th leg; 2 swellings on the left side and a notch on the right side of the genital segment. E. tanseii described from Sagami Bay (OмоRI, $1965)$ resembles very closely $E$. venusta, but in this species both outer and inner lobes of the terminal segment of the endopod of the 2 nd antenna bear 6 setae, and the 
right side of the genital segment is very smooth and straight. Since it was established, however, the species has not been collected again. There are several specimens which have the same characteristic in the genital segment as $E$. tanseii, but they resemble $E$. venusta in the other structures. The variation in the shape of the genital segment of $E$. venusta is not clearly understood. However, as the segment seems to have some minute changes, in the present paper they were identified with $E$, venusta. At present, the number of setae on the lobes of the terminal segment of the 2nd antenna is considered to be fixed in the genus Euchirella. But if $6+6$ setae observed in $E$. tanseii is an abnormal type (the species was described from single female specimen), $E$. tanseii becomes a synonym of $E$. venusta. From this point of view, there is a possibility that $E$. speciosa described by Grice and Hulsemann (1968) is also a synonym of $E$. venusta.

\section{PSEUDOCHIRELLA SARS, 1920 \\ Pseudochirella polyspina BRODSKY, 1950}

(Fig. 2, a-j)

Pseudochirella polyspina Brodsky, 1950, p. 185, fig. 102; TANAKA, 1957, p. 197, fig. 55, a-f; Grice and Hulsemann, 1967, p. 15.

Occurrence: Sta. 83, 2o, 10 (juv.); Sta. 108, 2o; Sta. 111-2, 1ठ̋; Sta. 116, 1 ; Sta. 120, 1q; Sta. 121-1, 4q; Sta. 121-2, 1 ㅇ.

Descriptive notes: Female, $5.70-6.40 \mathrm{~mm}$; male, $4.65 \mathrm{~mm}$.

In the male the cephalothorax and abdomen are in the proportional lengths of 66 to 34. The head is fused. The lateral margin of the last thoracic segment is rounded : it is devoid of any lateral spines. The rostrum resembles that of the female: it is directed downwards.

The abdominal segments and furca have the following proportional lengths:

segment

\begin{tabular}{rrrrrc}
1 & 2 & 3 & 4 & 5 & furca \\
\hline 16 & 30 & 21 & 18 & 2 & 13
\end{tabular}$=100$

The 2nd, 3rd, and 4th segments are fringed with fine spinules on the distal margin. The furcal ramus is as long as wide.

The 1st antenna extends about to the distal margin of the 4th abdominal segment: it measures $5.1 \mathrm{~mm}$ in length: the segments are in the following proportional lengths:

\begin{tabular}{|c|c|c|c|c|c|c|c|c|c|c|c|c|c|}
\hline \multirow{2}{*}{\multicolumn{2}{|c|}{ segment }} & & 1 & 2 & 3 & 4 & 5 & 6 & $8-9-10$ & 11 & $12-13$ & 14 & 15 \\
\hline & & & 65 & 55 & 34 & 28 & 31 & $28 \quad 30$ & 69 & 28 & 69 & 39 & 48 \\
\hline 16 & 17 & 18 & 19 & 20 & 21 & 22 & 23 & $24-25$ & & & & & \\
\hline 48 & 55 & 45 & 67 & 63 & 41 & 51 & 53 & 53 & 1000 & & & & \\
\hline
\end{tabular}


The 2nd antenna has a 7-segmented exopod which is 1.5 times the length of the endopod. The 1st segment of the exopod has no setae; the 2nd segment has a small process carrying a minute seta. The endopod has 7 setae on the outer lobe, and 8 setae on the inner lobe. The mandible palp is well developed: the cutting blade is

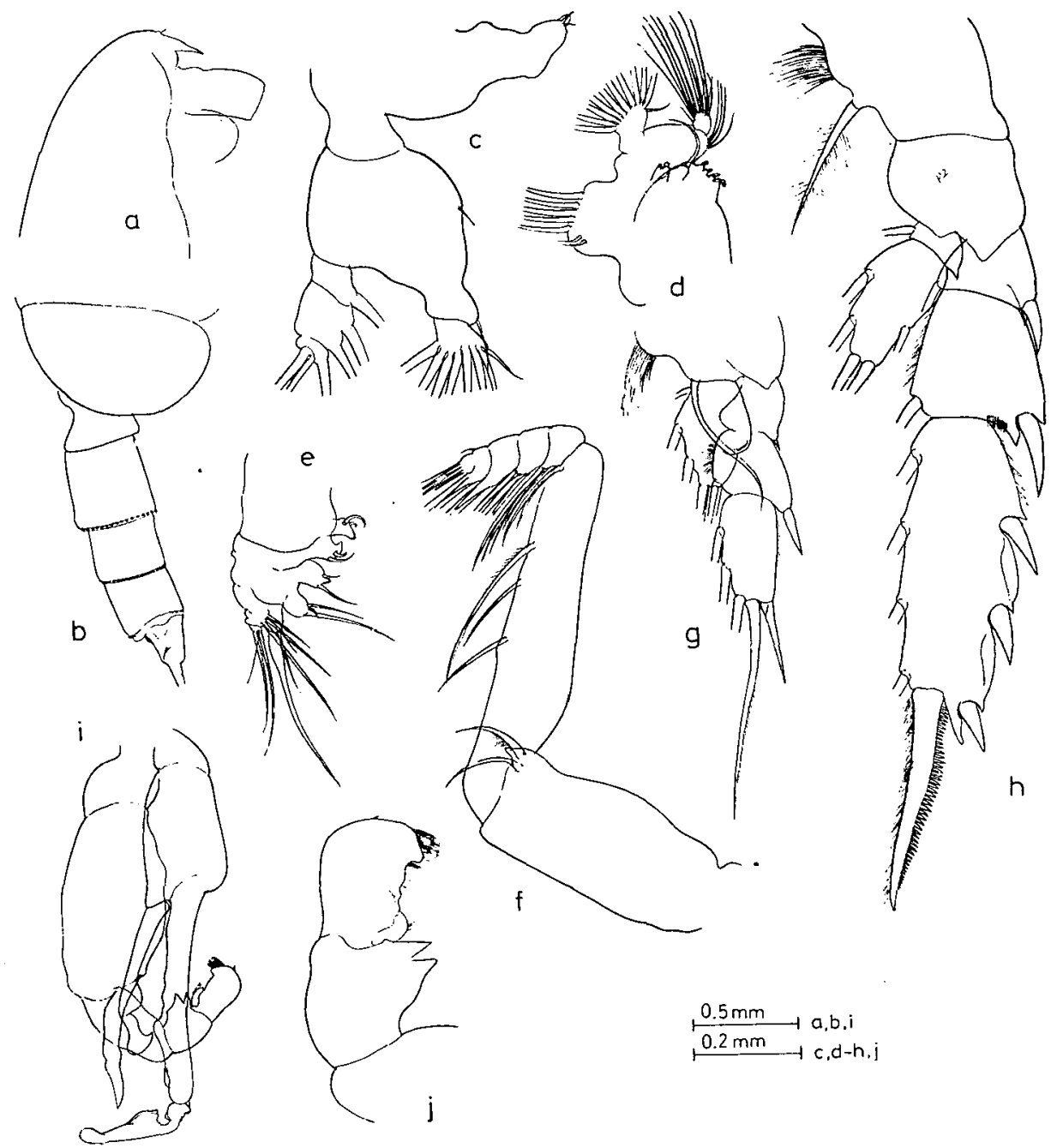

Fig. 2. Pseudochirella polyspina Brodsky, male: a, head, lateral view; $b$, last thoracic segment and abdomen, lateral view; c, mandible; d, 1st maxilla; e, 2nd maxilla; f, maxilliped; g, 1st leg; h, 2nd leg; i, 5th pair of legs; j, 2nd and 3rd segments of exopod of left 5 th leg.

small; it has no teeth. The 1st maxilla has the following numbers of setae on the various lobes: 5 long and 2 small setae on the outer lobe; 11 setae on the exopod; $6+4+4$ setae on the endopod; 4 setae on the 2 nd basal segment; an apical seta on the reduced 3 rd inner lobe: the 2 nd inner lobe is rudimentary: the lst inner lobe 
has 4 rudimentary setae. The 2 nd maxilla is reduced: it has the following numbers of setae on the various lobes: 6 long setae on the endopod; 2 setae and 1 small process on the 1st to 3rd lobes, respectively; 3 setae on the 4th lobe; 1 strong and 2 short setae on the 5th lobe. The maxilliped is well developed: the 2nd basal segment is 1.4 times the length of the lst one: the endopod is furnished with usual numbers of setae on the 1 st to 5 th segments.

The 1st leg has a 3-jointed exopod and a 1-jointed endopod: the 1st segment of the exopod has an outer marginal spine. The 2 nd leg has a 3 -jointed exopod and a 2-jointed endopod. The 3rd and 4th legs have each 3-jointed exopod and endopod. The 5 th pair of legs resembles that of $P$. spinifera: in the left leg the 2 nd segment of the exopod is furnished with 2 processes on the inner distal margin, whereas in the right leg the distal segment is deeply notched at the inner proximal margin.

Remarks: The present specimen closely resembles $P$. cryptospina or $P$. notacantha in the structure of the 5 th pair of legs. However, the latter 2 species bear lateral spines on the last thoracic segment. This is the first record of the male specimen of $P$. polyspina.

The distribution of the species has been reported from the northwestern Pacific and the Sea of Okhotsk (Brodsky, 1950), the Izu region (TANAKa, 1957), and the western Indian Ocean (Grice and Hulsemann, 1967). In the Izu region it is generally found in the water deeper than $700 \mathrm{~m}$.

\section{Pseudochirella pustulifera (SARS, 1905)}

(Fig. 3, a-f)

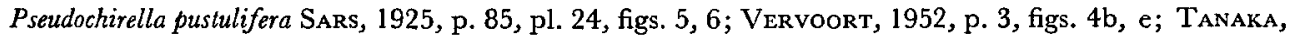
1957, p. 192, fig. 54, a-g.

Euchirella wolfendeni FARRAN, 1908, p. 38, pl. 2, figs. 18, 19, pl. 4, fig. 3.

Chirundina pustulifera, WIтн, 1915, p. 145, fig. 6, text-fig. 39 .

Occurrence: Sta. 93-1, 1 ; Sta. 93-2, 3o; Sta. 110, 1ð; Sta. 113, 1 9 ; Sta. 114, 2o; Sta. 115-2, 2o; Sta. 117-1, 1; Sta. 117-2, 2우 Sta. 119, 1; Sta. 121-2, 2 ㅇ․

Descriptive notes: Female, 5.77-6.45 mm; male, $5.51 \mathrm{~mm}$.

In the male the cephalothorax and abdomen are in the proportional lengths of 74 to 26 . The head is fused with the 1 st thoracic segnent, as are the 4th and 5th thoracic segments. The frontal margin of the head is rounded. The lateral distal margin of the last thoracic segment is not produced, but smoothly rounded in lateral view. The rostrum is long and curved: it is directed posteriorly downwards.

The abdominal segments and furca have the following proportional lengths:

segment

\begin{tabular}{rrrrrr}
1 & 2 & 3 & 4 & 5 & furca \\
\hline 17 & 30 & 20 & 19 & 2 & 12
\end{tabular}$=100$


The 2nd to 4th thoracic segments are fringed with spinules on the distal margin. The furcal ramus is as long as wide.

The lst antenna is $5.0 \mathrm{~mm}$ in length: it extends about to the distal margin of the 2nd abdominal segment: the segments have the following proportional lengths:

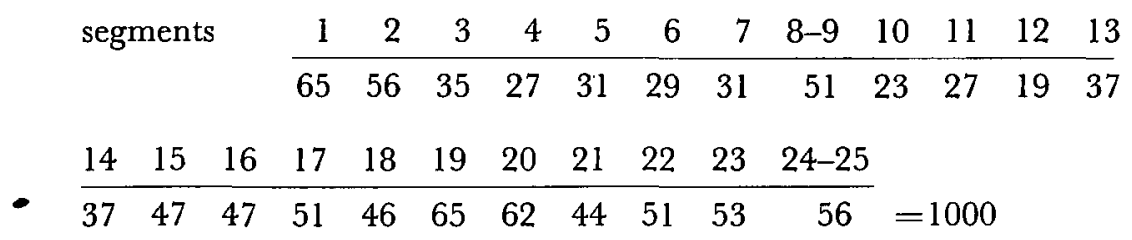

The segments 12 and 13 are partially fused.

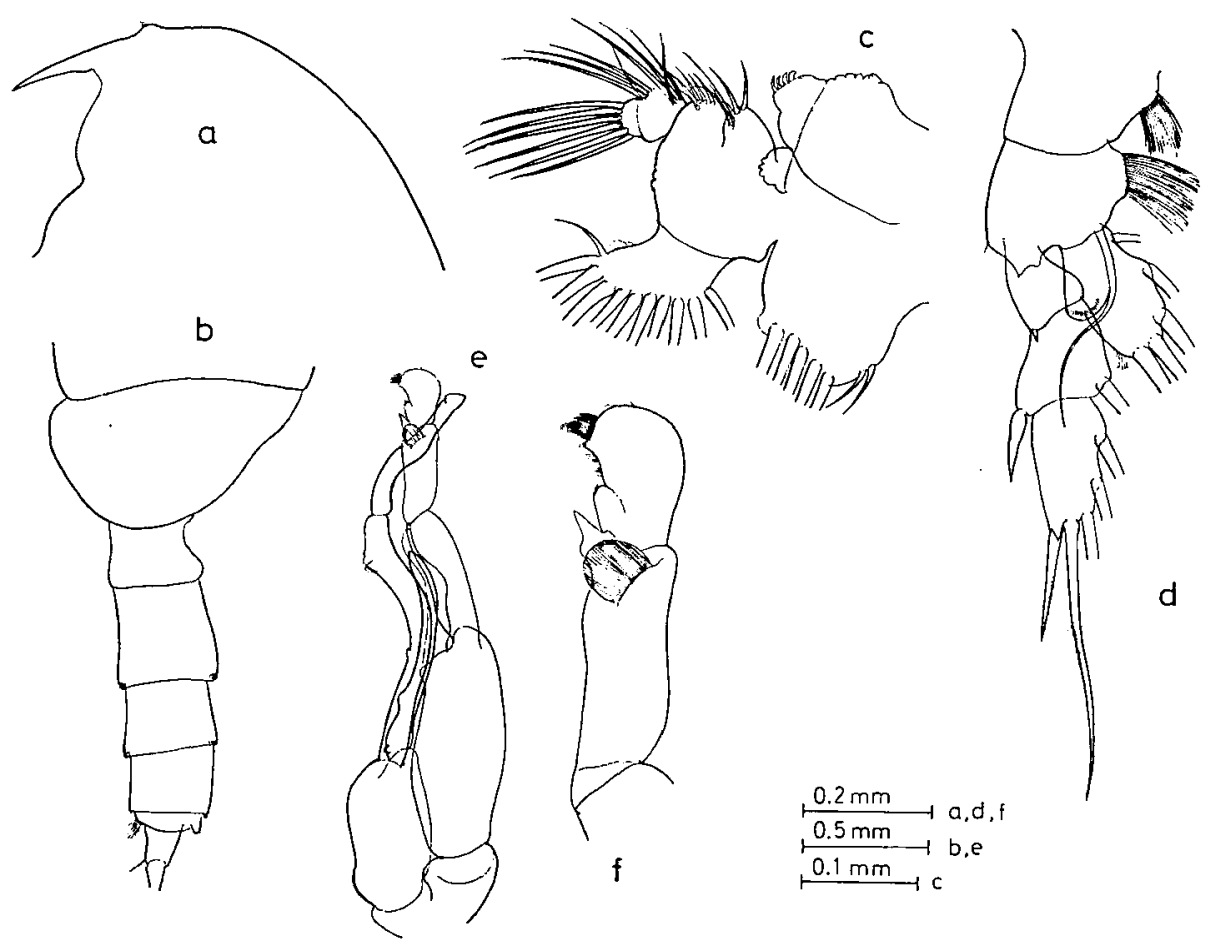

Fig. 3. Pseudochirella pustulifera (Sars), male: $a$, head, lateral view; b, last thoracic segment and abdomen, lateral view; c, 1st maxilla; d, 1st leg; e, 5th pair of legs; $\mathbf{f}$, 2nd and 3rd segments of exopod of left 5 th leg.

In the 2nd antenna the exopod is as long as the endopod: the endopod is furnished with 6 long setae on the outer lobe, and 7 long and a minute setae on the inner lobe. The mandible resembles that of $P$. polyspina. The 1st maxilla has 7 setae on the outer lobe, 11 setae on the exopod, $5+4+4$ setae on the endopod, 5 setae on the 2 nd basal segment, 4 setae on the 3rd inner lobe, 2 rudimentary setae on the 2 nd inner lobe, 
and 7 rudimentary setae on the 1 st inner lobe. The 2 nd maxilla and maxilliped resemble those of $P$. polyspina.

The 1st leg has a 3-jointed exopod and a 1-jointed endopod: the 1st segment of the exopod has an outer marginal spine. The 5 th pair of legs has a similar structure to that of $P$. polyspina, but the 2nd segment of the exopod of the left leg is furnished with single process on the inner distal margin: this pointed process is accompanied with a semicircular striated process.

Remarks: The present male specimen resembles $P$. polyspina in the structure of the last thoracic segment. However, the species can be distinguished from the latter by the existance of the ornamentation on the 2nd segment of the exopod of the left 5 th legs. The authors think that it is reasonable to regard the present male specimen as the male of $P$. pustulifera which has hitherto been undescribed. WILson (1932) reported the male of $P$. pustulifera under the name Chirundina pustulifera, but it must be not Pseudochirella but other species of Aetideidae.

The distribution of the female has been reported from Irish water (FARRAN, 1908), the northeastern Atlantic (SARS, 1925), the Izu region (TANAKA, 1957), and the western Indian Ocean (Grice and Hulsemann, 1967). The species usually occurs in the water deeper than $1000 \mathrm{~m}$ in the Izu region.

\section{Pseudochirella spinifera BRODSKY, 1950}

(Fig. 4, a-k)

Pseudochirella spinifera BRodsky, 1950, p. 188, fig. 104.

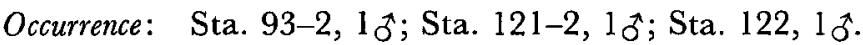

Descriptive notes: Male, $5.10-5.20 \mathrm{~mm}$.

The cephalothorax and abdomen are in the proportional lengths of 74 to 26 . The head and the 1st thoracic segment as well as the 4th and 5th thoracic segments are fused. The lateral distal margin of the last thoracic segment is rounded and provided with a lateral spine on each side of the segment: the spine is slender and slightly curved. The rostrum is long and curved downwards.

The abdominal segments and furca are in the following proportional lengths:

segment

\begin{tabular}{rrrrrc}
1 & 2 & 3 & 4 & 5 & furca \\
\hline 20 & 27 & 20 & 16 & 7 & 10
\end{tabular}$=100$

The 2nd to 4th segments are fringed with fine spinules on the distal margin. The furcal ramus is a little wider than long.

The 1st antenna extends to the end of the 3rd abdominal segment: it is about $4.9 \mathrm{~mm}$ in length. The segments of the left antenna are in the following proportional lengths: 


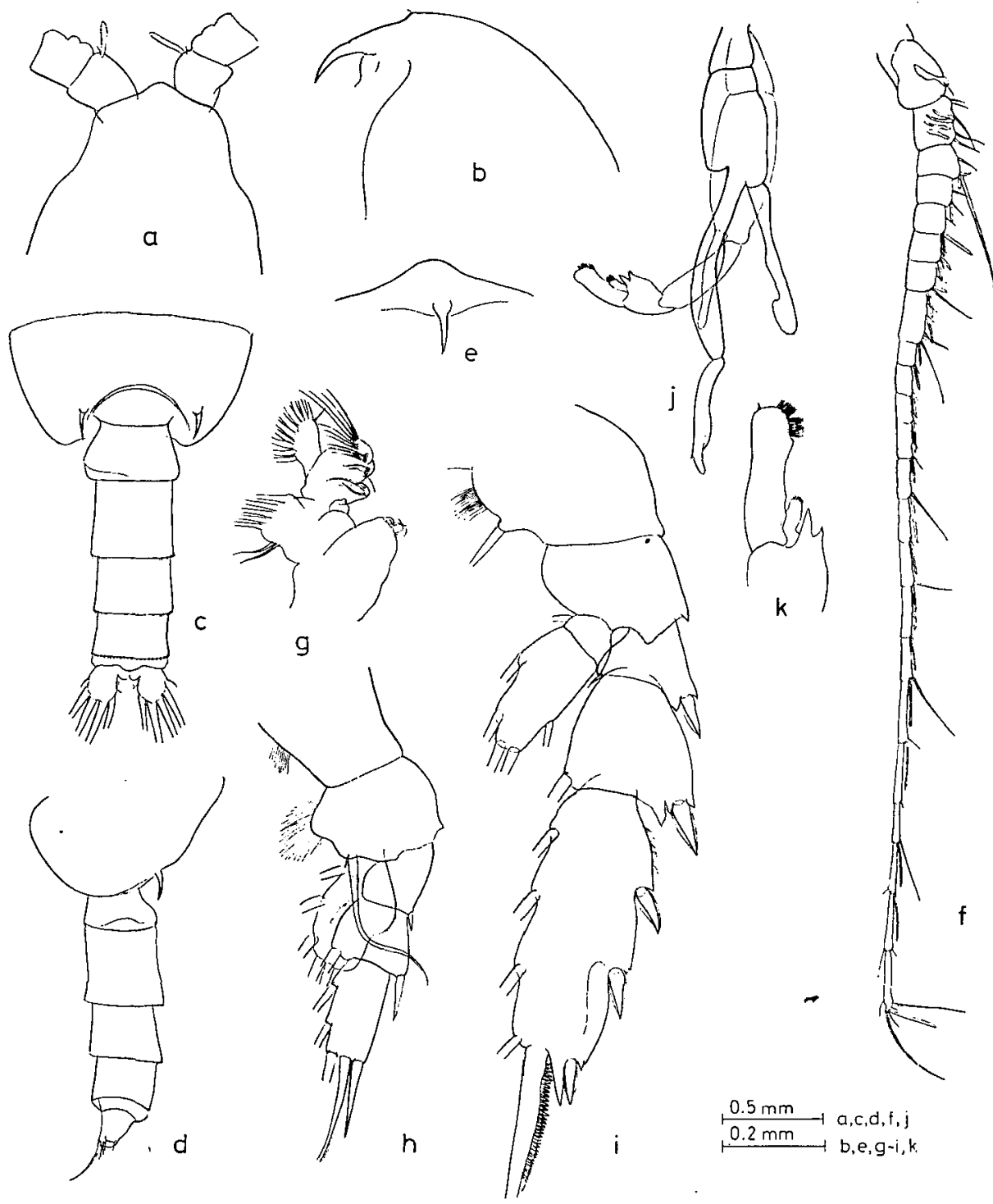

Fig. 4. Pseudochirella spinifera Brodsky, male: a, head, dorsal view; $b$, the same, lateral view; $c$, last thoracic segment and abdomen, dorsal view; $d$, the same, lateral view; e, rostrum; f, 1st antenna; g, 1st maxilla; h, 1st leg; i, 2nd leg; $j$, 5th pair of legs; k, 2nd and 3rd segments of exopod of left 5 th leg.

\begin{tabular}{|c|c|c|c|c|c|c|c|c|c|c|c|c|c|c|c|}
\hline \multicolumn{3}{|c|}{ segment } & 1 & 2 & 3 & 4 & 5 & 6 & 7 & $8-9$ & 10 & 11 & $12-13$ & 14 & 15 \\
\hline & & & 66 & 53 & 35 & 27 & 30 & 27 & 29 & 51 & 22 & 27 & 68 & 39 & 47 \\
\hline 16 & 17 & 18 & 19 & 20 & 21 & 22 & 23 & $24-$ & & & & & & & \\
\hline 47 & 51 & 45 & 66 & 64 & 45 & 49 & 57 & 55 & & 100 & & & & & \\
\hline
\end{tabular}


The segments 9 and 10 are partially fused.

The 2nd antenna has the exopod 1.5 times the length of the endopod. The 1st and 2nd segments of the exopod have no marginal setae. In the endopod the outer lobe has 6 , and the inner lobe has 8 setae. The mandibular palp is broad, and is furnished with a small marginal seta. The cutting edge is reduced. The 1st maxilla has 7 setae on the outer lobe; the exopod has 10 setae; the endopod including the 2 nd basal segment has 9 setae; the 1st to 3rd inner lobes are reduced, and are funished with rudimentary setae. The 2 nd maxilla is much reduced. The maxilliped is well developed.

The 1st leg has a 3-jointed exopod and a 1-jointed endopod: the 1st segment of the exopod has a marginal spine. The 2nd leg has a 3-jointed exopod and a 2jointed endopod. The 3rd and 4th legs have each 3-jointed exopod and endopod. In the 5th leg the distal segment of the left exopod is slender: the distal segment of the right exopod has no incision.

Remarks: The present male specimen resembles $P$. notacantha or $P$. polyspina in having lateral spines on the lateral corner of the last thoracic segment. However, in $P$. notacantha the distal segment of the exopod of the left 5 th leg is broad, and in $P$. polyspina the distal segment of the exopod of the right 5th leg has a deep incision on the inner margin.

The species has been found in the deep water of the northwestern Pacific Ocean and the Sea of Okhotsk (Brodsky, 1950).

\section{Pseudochirella tuberculata TANAKA, 1957}

Pseudochirella tuberculata Tanaka, 1957, p. 195, fig. 56; Grice and Hulsemann, 1967, p. 15.

Occurrence: Sta. 93-2, 2o; Sta. 94, 1 ; Sta. 97-2, 2q; Sta. 112, 1 \%; Sta. 114, 3 ; : Sta. 115-2, 1; Sta. 121-2, 1 ㅇ․

Remarks: Female, $5.70-6.00 \mathrm{~mm}$. The species is easily recognized in having a small rounded process on right side of the distal lateral margin of the last thoracic segment. The shape of the genital segment is also quite characteristic.

The species is usually distributed in the layers deeper than $700 \mathrm{~m}$ in the $\mathrm{Izu}$ region. Recently, it has been obtained in the western Indian Ocean (GrICE and HulsemanN, 1967).

\section{Pseudochirella vervoorti sp. nov.}

(Fig. 5 a-n)

Occurrence: Sta. 111-2, 1 9 ; Sta. 117-2, 1 \%.

Descriptive notes: Female, 5.66 and $5.71 \mathrm{~mm}$ (Holotype).

The cephalothorax and abdomen are in the proportional lengths of 82 to 18 . The head is separated from the lst thoracic segment as are the 4th and 5 th segments. 


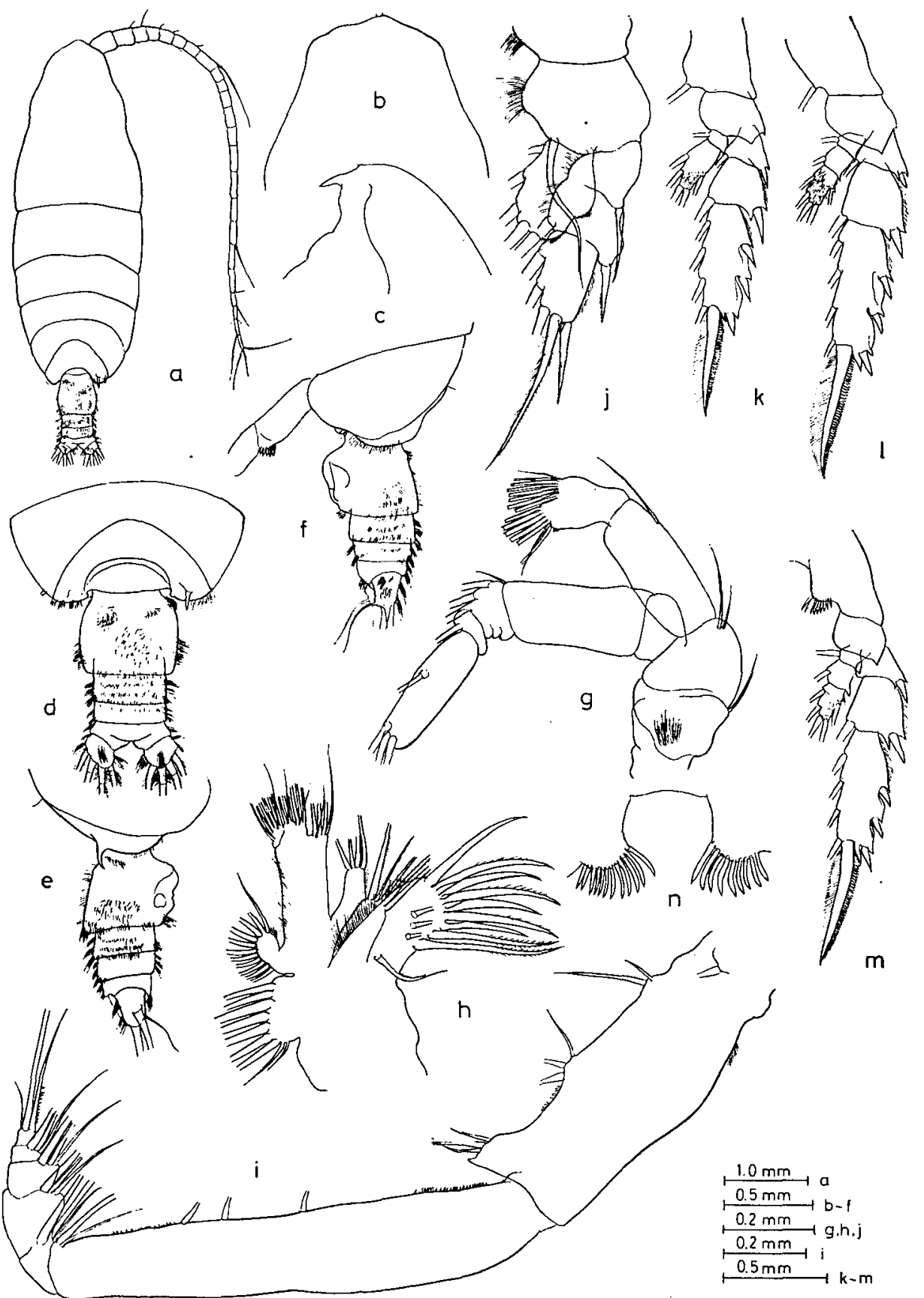

Fig. 5. Pseudochirella vervoorti sp. nov., female: $a$, whole body, dorsal view; $\mathrm{b}$, head, dorsal view; c, the same, lateral view; d, last thoracic segment and abdomen, dorsal view; e, the same, lateral view from right side; $f$, the same, lateral view from left side; $g$, 2nd antenna; $h$, 1 st maxilla; i, maxilliped; $j$, 1st leg; $k$, 2nd leg; 1, 3rd leg; $m, 4$ th leg; $n$, inner margin of 1st basal segment of 4 th pair of legs. 
The cephalothorax is 2.5 times as long as wide. The frontal margin of the head is rounded. The lateral distal margin of the last thoracic segment is rounded and is furnished with a lateral spine only on the right side. The lateral distal margin of the last thoracic segment is haired. The rostrum is directed downwards.

The abdominal segments and furca have the following proportional lengths:

segment

\begin{tabular}{rrrrr}
$1-2$ & 3 & 4 & 5 & furca \\
\hline 49 & 15 & 11 & 7 & 18
\end{tabular}$=100$

The genital segment is as long as wide, and is furnished with hairs. The furcal ramus is as long as wide: the other segments and furcal rami are also densely haired: the furcal ramus is as long as wide.

The 1st antenna extends to the distal margin of the 4th abdominal segment. The segments are in the following proportional lengths:

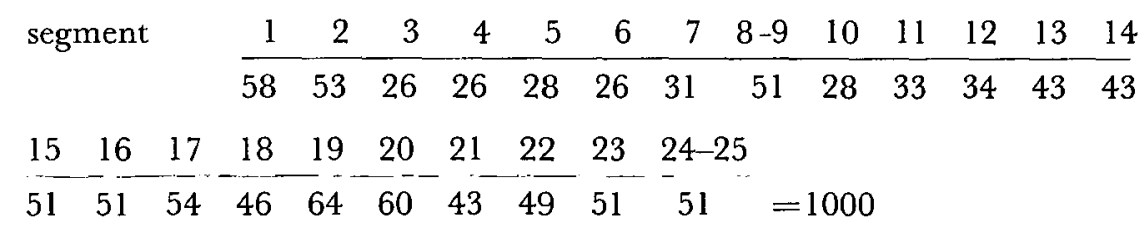

The 2nd antenna has the exopod which is 1.7 times the length of the endopod. The outer lobe of the endopod is furnished with 7 setae, and the inner lobe with 8 setae. The mandibular palp is furnished with 3 marginal setae: the exopod is a little more than the length of the endopod: the endopod has 11 setae on the distal margin. The 1st maxilla has 9 setae on the outer lobe, 11 setae on the exopod, $7+$ $4+4$ setae on the endopod, 5 setae on the 2nd basal segment, 4 setae on the 3rd inner lobe, 5 setae on the 2 nd inner lobe, and 13 setae on the 1st inner lobe. The 2 nd maxilla is of the usual structure: the 1st to 5 th segments are each furnished with 3 setae; the endopod has 6 long and one short setae. In the maxilliped the 2nd basal segment is 1.3 times the length of the 1st basal one: the $2 \mathrm{nd}$ basal segment is furnished with a row of spinules on the distal and proximal parts of the inner margin: the innermost seta of the distal segment of the endopod has distinct spinules on the proximal part.

The 1st leg has a 3-jointed exopod and a 1-jointed endopod: the 1st and 2nd segments of the exopod are incompletely fused: the lst segment of the exopod has an outer marginal spine: the endopod is furnished with minute spinules on the outer margin. . The 2nd leg has a 3-jointed exopod and a 2-jointed endopod: distal part of the 2nd segment of the endopod bears a number of spinules. The 3rd and 4th legs have each 3-jointed exopod and endopod: the 3rd segment of the endopod of each leg is furnished with dense spinules. In the 4th leg the lst basal segment has 12 tube-like bristles on the inner margin of the left leg, and 9 bristles on the right leg. The terminal spine of the exopod is very finely serrated: it has about 90 teeth. 
Remarks: The present species resembles P. semispina VERvoort (1949) recorded in the Malay Archiperago region. However, it differs distinctly from the latter by the site of the hairs on the abdominal segments, and the proportional lengths of the exopod and endopod of the 2nd antenna. In the present species the 2nd pair of legs has a 2 -jointed endopod, whereas $P$. semispina has a 1 -jointed endopod. The lst basal segment of the 4th legs has 9 and 12 bristles on the inner margin in the former species, but it has 7-8 bristles in the latter. This new copepod is named in honor of Dr. Willem Vervoort, Rijksmuseum van Natuurlijke Historie, Leiden.

\section{REFERENCES}

The only papers which are not included in our previous paper Additional report on calanoid copepods from the Izu region. Part 1. Euchaeta and Pareuchaeta (1968) are listed.

Grige, G.D. and K. Hulsemann, 1967. Bathypelagic calanoid copepods of the western Indian Ocean. Proc. U.S. Nat. Mus., vol. 122, no. 3583, pp. 1-67.

and 1968. Calanoid copepods from midwater trawl collections made in the southeastern Pacific Ocean. Pacific Sci., vol. 22, pp. 322-335.

Omori, M. 1965. A new species of Euchirella (Copepoda) from Sagami Bay, middle Japan. J. Oceanogr. Soc. Japan, vol. 21, pp. 60-65.

PARk, T.S. 1968. Calanoid copepods from the central North Pacific Ocean. Fishery Bull. Fish Wildl. Serv. U.S., vol. 66, pp. 527-572.

TANAKA, O. 1957. The pelagic copepods of the Izu region, middle Japan. Systematic account, IV. Family Aetideidae (part 2). Publ. Seto Mar. Biol. Lab., vol. 6, pp. 169-207.

TANAKA, O. and M. OMORI, 1968. Additional report on calanoid copepods from the Izu region. Part 1. Euchaeta and Pareuchaeta. Ibid., vol. 16, pp. 219-261.

- and 1969. On Euchirella (Copepoda, Calanoida) collected chiefly by the U.S. Steamer Albatross from the Pacific Ocean. Ibid., vol. 17, pp. 33-65.

Vervoort, W. 1949. Some new and rare Copepoda Calanoida from East Indian Seas. Zool. Verh., Leiden, no. 5, pp. 1-53.

1952. Copepoda, sub-order Calanoida, family Aetideidae, genus Pseudochirella. Zooplankton sheet, Cons. Explor. Mer, no. 48, pp. 1-4.

Corrections to Publications of the Seto Marine Biological Laboratory.

Vol. XV1, No. 4-paper by TANAKa and OMORI: "Additional report on calanoid copepods from the Izu region. Part 1. Euchaeta and Pareuchaeta."

Page 226: Fig. 3-caption, “...P. P. rubra; ..." should read “... P. P. prudens; Q. P. rubra; ..."

Page 227: Fig. 4-caption, “... P. P. rubra; ...” should read "... P. P. prudens; Q.P.rubra; ..." 